\title{
SOME GROSS MORPHOLOGICAL STUDIES ON THE INTERNAL ANATOMY OF THE COMMON CARP FISH (CYPRINUS CARPIO) IN EGYPT
}

Farag, F.M.M., Wally, Y.R., Daghash, S.M. and Ibrahim, A.M.

Department of Anatomy and Embryology Faculty

of Veterinary Medicine Cairo University

\begin{abstract}
The present work was carried out on ten of fresh carp fishes with avarage weight range $1.5-3.5 \mathrm{~kg}$. The fishes were subjected to fine dissection to demonstrate the anatomy of the digestive, respiratory and urogenital organs. Carp fish had a terminal moth, no any teeth on both jaws and this was compensated by well-developed pharyngeal pad and pharyngeal teeth. No stomach could be observed but the beginning of the intestinal tract formed an intestinal swelling. The intestinal tract throughout its length formed three U-shaped loops. The liver was relatively large and formed of multiple hepatic fragments that surrounded and dispersed between most of the viscera. The gall bladder was a large sac situated on the right side of the intestinal swelling. Five pairs of gill arches were observed and the last pair united forming the pharyngeal bone. The swim bladder was two chambered and was physostomous type. The kidneys were differentiated into head and trunk kidneys. The ovaries were large oval bodies that occupied most of the abdominal cavity. The testes consisted of 5-6 irregular lobes.
\end{abstract}

The obtained results were photographed, described and discussed with their earlier studies.

Key words: Anatomy- Fish- Common carp. 


\section{INTRODUCTION}

The common carp (Cyprinus carpio) is a widespread freshwater fish in lakes, ponds and large rivers in Europe and Central Asia, but has been introduced practically everywhere outside its native geographical and climatic range. It is on the List of the world's 100 worst invasive species (Kottelat and Freyhof, 2007). Common carp is one of the most important fish species used in fish farming (Bakos and Gorda, 2001). Many studies have been done on the anatomy of the fish ( $A L$ hussaini,1949; Scott and Crossman, 1973; Petrick, 1975; Meyer et al., 1977; Sherwood and Thomas, 1977; Kumar and Tembhre,1996; Gerham,1997; Zayed and Mohamed, 2004; Ahmed et al., 2008). The aim of this study was to investigate the internal anatomy of the common carp (Cyprinus carpio) as a trial to extend our knowledge on the fish anatomy.

\section{MATERIAL AND METHODS}

This work was carried out on the common carp (Cyprinus carpio) fish. Ten fishes varied in weight from $1.5-3.5 \mathrm{~kg}$. were used the fishes used were either still living or in fresh stat.

For exposing the viscera an incision was made through the midventral line of the fish from just cranial to the anus and continued with blunt-tipped scissors cranially to the level of the pectoral fin. The body wall reflected upward, with careful cranial and caudal incisions to expose all the viscera. The operculum was removed to expose the gills.

The gills of the left side were then removed to expose the mouth cavity and pharynx. All the viscera were first carefully dissected using finger and back of the blade and photographed in situ, then carefully taken out to be examined and photographed separately then preserved in jars containing $10 \%$ formalin solution to be exposed in the anatomy museum at the Faculty of Veterinary Medicine Cairo University.

$\overline{\text { Kafrelsheikh Vet. Med. J. Vol. } 11 \text { No. } 1 \text { (2013) }}$ 


\section{RESULTS}

\section{I- Digestive system:}

The mouth (Fig. 1/1) was protrusive, terminally situated, and with the maxilla slightly overlapped the mandible. The barbells (Fig.1, 2/2) were two pairs, one pair located on the middle of the upper lip and was short and thin while the other pair was laterally situated at the mouth commissure and was long and thick.

The mouth cavity (Fig. 2, 3/3) of the carp was free from any teeth on both jaws. This was compensated by well-developed pharyngeal teeth. The tongue (Fig2/4) was attached to the floor of the mouth cavity by thin median frenulum (Fig2/5).

The pharynx (Fig3/6) was differentiated into two distinct portions cranial and caudal. The cranial portion (Fig3/6a) was wide and its roof lined with smooth mucous membrane whiles its lateral wall, containing the gill-slits. The caudal portion (Fig.3 /6b) of the pharynx contained the pharyngeal pad and pharyngeal teeth. The pharyngeal pad (Fig3/7) was small quadrilateral hard pad on the dorsal wall of the pharynx below the occipital region of the skull opposite to the pharyngeal teeth. The pharyngeal teeth $(\mathrm{Fig} 3,7 / 8)$ were located on the ventrolateral wall of the caudal portion of the pharynx on the pharyngeal bone. They were arranged in a triserial manner $(3: 1: 1)$, i.e. three medial large teeth and two successive smaller lateral ones.

The alimentary canal began with short esophagus (Fig5/9) and the stomach could not be observed, but the proximal portion of this tract formed was slightly wider forming an intestinal swelling.

$\overline{\text { Kafrelsheikh Vet. Med. J. Vol. } 11 \text { No. } 1 \text { (2013) }}$ 
The intestinal swelling (Fig5/10): was in the form of long straight tube, extending from the esophagus to the caudal end of the body cavity. This swelling was more wide cranially and gradually diminished as it proceeded caudally.

The intestinal tract from the caudal end of the intestinal swelling to the anus formed three U- shaped loops, each consisted of two limbs: an ascending limb and a descending limb.

The proximal loop (Fig5/11) began at the caudal end of the intestinal swelling, and consisted of two short limbs. The ascending limb (Fig5/11a) extended cranially to about the middle of the body-cavity where it curved forming a semicircular downward flexure and continued caudally as the descending limb (Fig5/11b) that extended again to the caudal part of the body cavity where it formed another semicircular downward flexure and continued as the middle loop.

The middle loop (Fig5/12) was the longest of the three loops forming the intestinal tract as it extended throughout the length of the body cavity. It began as an ascending limb (Fig5/12a) that extended cranially along the ventral wall forming a slight upward inclination and terminated at the transverse septum then formed a sharp downward flexure and returned back as a descending limb (Fig5/12b) that extended caudally to the caudal part of the body cavity where it formed an upward curve and continued as the distal loop.

The distal loop (Fig5/13) began as an ascending limb (Fig5/13a) that extended cranially to about the middle of the body where it formed a semicircular upward flexure and returned back as a descending limb (Fig5/13b) that extended caudally to the caudal part of the body cavity where it terminated at the anal pore (Fig.11/30). 
It was noticeable that only the cranial portion of the middle loop and the entire distal loop could be observed on the left side (Fig.5) of the body cavity while the rest of the intestinal tract was oriented on the right side. This means the intestinal tract while forming its three loops passed in an oblique manner from right to left and vice versa.

The liver (Fig.4, 6/14) was relatively large and formed of multiple hepatic fragments that surrounded and dispersed between most of the viscera. The gall bladder (Fig.5/15) was a large sac situated on the right side of the cranial part of the intestinal swelling.

The spleen (Fig.4, 5/16) was elongated dark red organ with broad cranial pole and pointed caudal pole, located on the right side of the cranial part of the intestinal swelling.

\section{II- Respiratory system:}

The respiratory system of the fish was formed mainly of the gills. These organs were located on the sides of the head, in special cavity called gill or opercular chamber covered externally by the operculum (Fig.3, 4/17) which made of a hard bony flap covering and protecting the gills. Carp fish contained five pairs of gill arches (Fig.7/18). On the lateral convex edge of each arch presented two rows of long feathery structure, the gills filaments (Fig.7/19), and each filament had lamellae with bright red coloration due to the plenty of its blood. The inner concave edge of each gill arch presented two rows of bony comb like projections called the gill rakers (Fig.7/20) which were short, thick and Kafrelsheikh Vet. Med. J. Vol. 11 No. 1 (2013) 
narrow spaced. The fifth gill arch was found in the form of short rod of bone that united with its fellow forming Y-shaped pharyngeal bone (Fig.7/21) which carried the pharyngeal teeth.

The swim bladder, gas bladder, fish maw or air bladder (Fig.4, 5, 9/22) was in the form gas-filled, membranous sac that located just ventral to the vertebral column and kidneys. It was divided into two unequal chambers; cranial and caudal. The cranial chamber (Fig.4, 5, 9/22a) was larger formed about $2 / 3$ bladder size and ended cranially with a rounded tip that lied in contact with the septum transversum. The caudal chamber (Fig.4, 5, 9/22b) was smaller and narrower with caudal narrow tip. The two chambers were demarcated from each other by a narrow constriction, the isthmus (Fig.4, 5/22c). The cavities of both chambers were undivided by any internal septa and were communicated through narrow internal foramen (Fig.5/24). The swim bladder of the common carp could be considered as an open, physostomous type, as it was connected to the cranial portion of the esophagus through a pneumatic duct (Fig.4, 5/23). This duct was observed to begin from the cranioventral aspect of the posterior chamber and extended cranially to be terminated into the dorsal aspect of the esophagus.

The transverse septum (Fig.4, 9, /25) was in the form of thin transparent membrane between abdominal and pericardial cavities. It could be considered as the fish diaphragm. 


\section{III- Urogenital system:}

The urogenital organs were mainly represented by the kidneys and gonads.

The kidneys (Fig.8/26) were narrow, elongated organs dark reddish brown in colour, situated in the roof of the abdominal cavity, related dorsally to the vertebral column and ventrally to the swim bladder. They were divided according their location into two portions; the cranial portion or the head kidney and the caudal portion or the trunk kidney. The head kidneys (Fig.8/26a) were in the form of two oval bodies and were separated from each other in the midline and also from the trunk kidneys by wide gap. The trunk kidneys (Fig.8/26b) could be differentiated into cranial thick and caudal thin portion. In between these portions, the trunk kidney formed an expanded three sided ventral lobe (Fig.8/26c) on the level of the isthmus of the swim bladder.

The gonads were represented by paired ovaries or testes. The ovaries (Fig.4, 6, 9, /27) were in the form of two large oval bodies with broad cranial pole and pointed caudal one that occupied most of the abdominal cavity, from the septum transversum cranially to the anus caudally. Multiple ripe eggs could be observed filling the ovaries. The testes (Fig.10/28) were very large bright red organs that demarcated by deep fissured into 5-6 irregular lobes and located between the swim bladder and intestines. From the caudal end of both gonads extended short tube called common oviduct or sperm duct (Fig.10/29) that terminated at the urogenital pore (Fig.11/31) which formed an independent opening located cranial to the anal pore. 


\section{Legend For The Figures}

1- Mouth

2- Barbells

3- Mouth cavity

4- Tongue

5- Median frenulum

6- Pharynx

6a-Cranial portion

6b-Caudal portion

7- Pharyngeal pad

8- Pharyngeal teeth

9- Esophagus

10- Intestinal swelling

11- The proximal loop

11a-Descending limb

11b- Ascending limb

12- Middle loop

12a-Descending limb

12b-Ascending limb

13- Distal loop

13a- Descending limb

13b- Ascending limb

14- Liver

15- Gall bladder
16- Spleen

17- Operculum

18- Gill arches

19- Gills filaments

20- Gill rakers

21- Pharyngeal bone

22- Swim bladder

22a- Cranial chamber

22b-Caudal chamber

22c-Isthmus

23- Pneumatic duct

24- Internal foramen

25- Transverse septum

26- Kidneys

26a-Head kidneys

26b-Trunk kidneys

26c-Ventral lobe

27- Ovaries

28- Testes

29- Common sperm duct

30- Anal pore

31- Urogenital pore

32- H. Heart

Kafrelsheikh Vet. Med. J. Vol. 11 No. 1 (2013) 


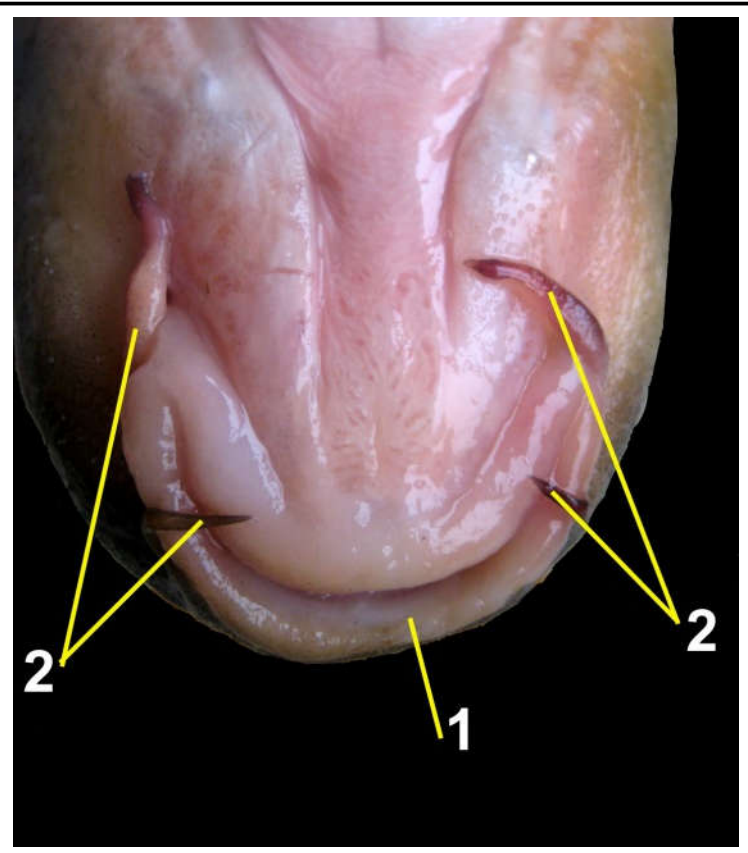

Fig (1): A photograph showing the Mouth of the common carp (Ventral view)

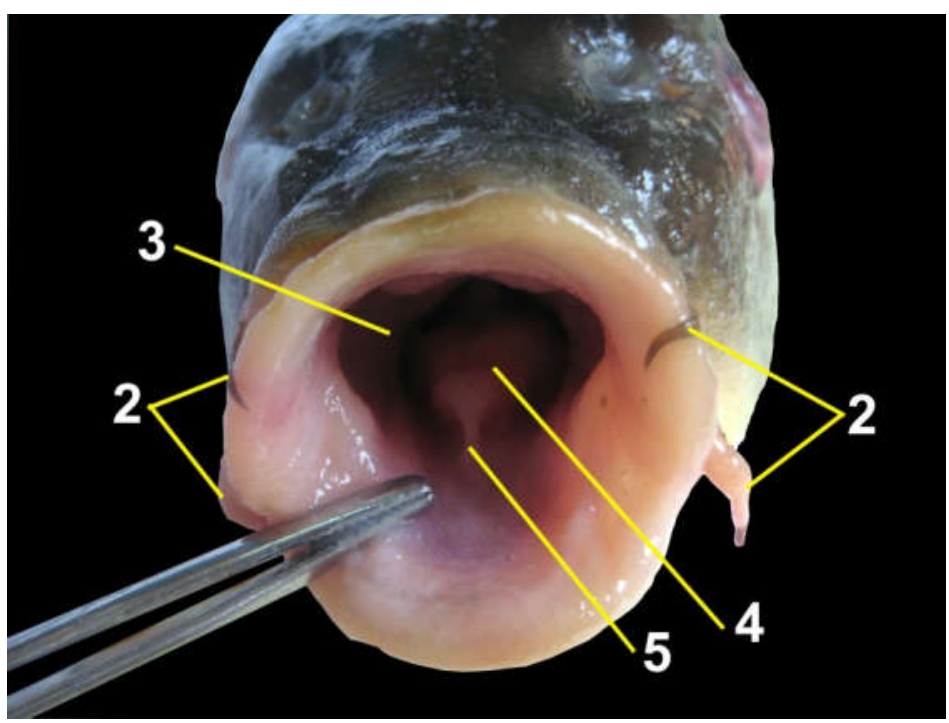

Fig (2): A photograph showing the mouth cavity and tongue of the common carp

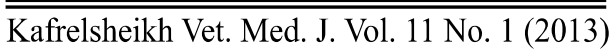


Farag, F.M.M. et., al.

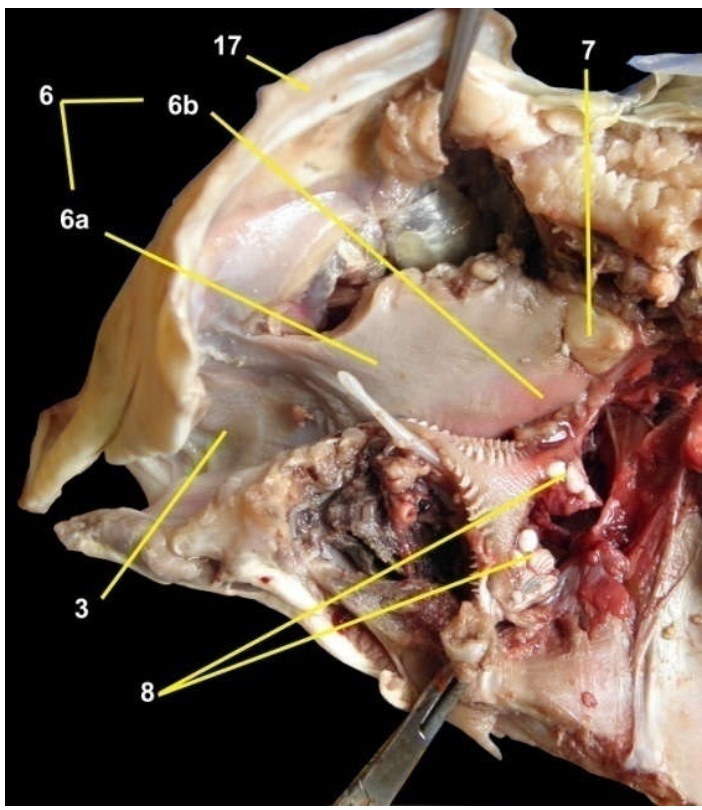

Fig (3): A photograph showing the mouth cavity and pharynx of the common carp

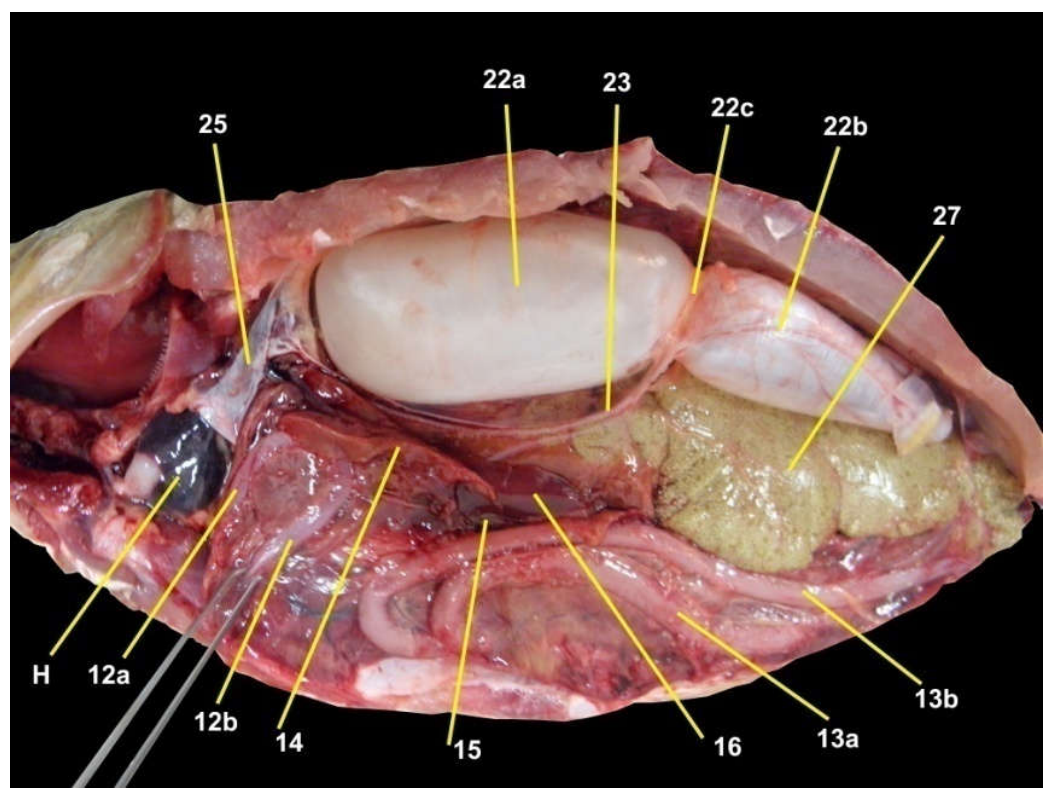

Fig (4): A photograph showing the viscera of the common carp in situ (Left view)

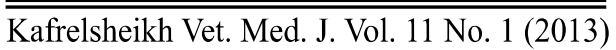


some gross morphological studies on the internal ...

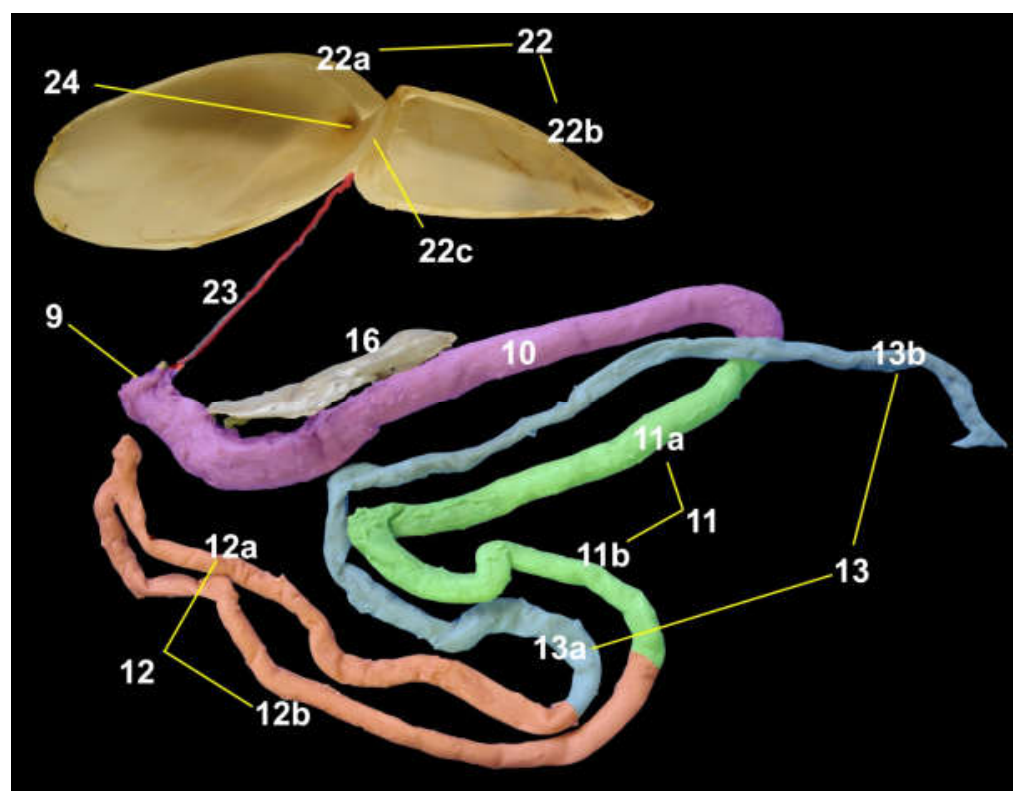

Fig (5): A photograph showing the intestinal arrangement of the common carp (colored photo). Swim bladder opened

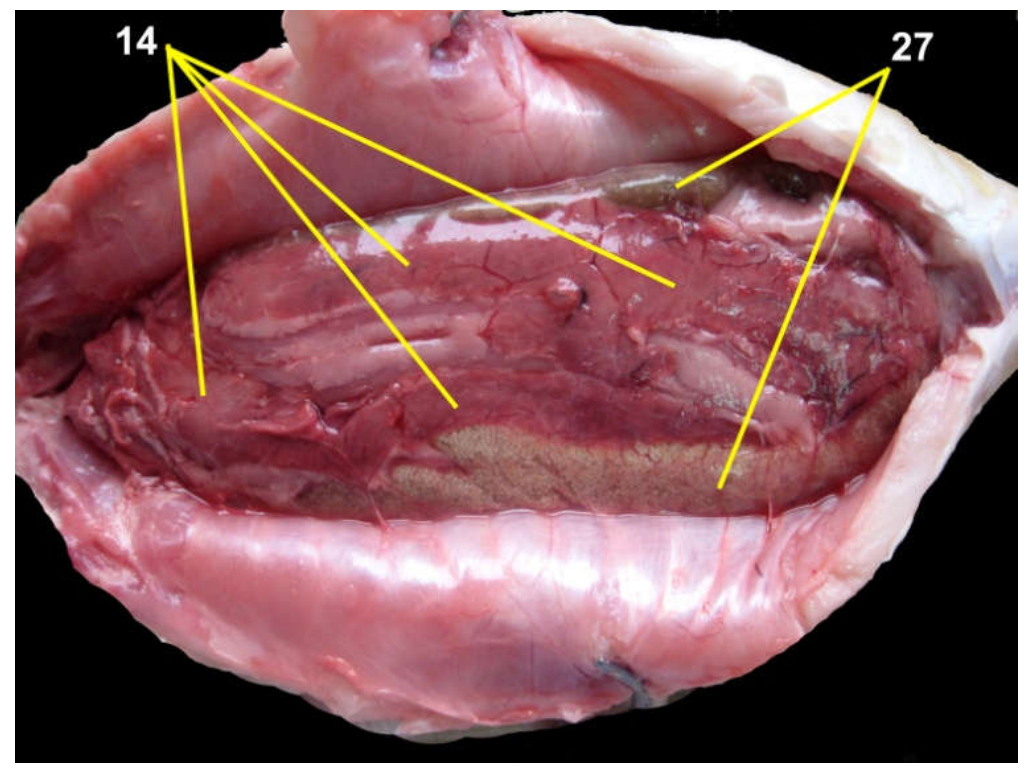

Fig (6): A photograph showing the liver and ovary of the common carp in situ (Ventral view)

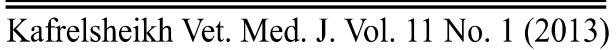




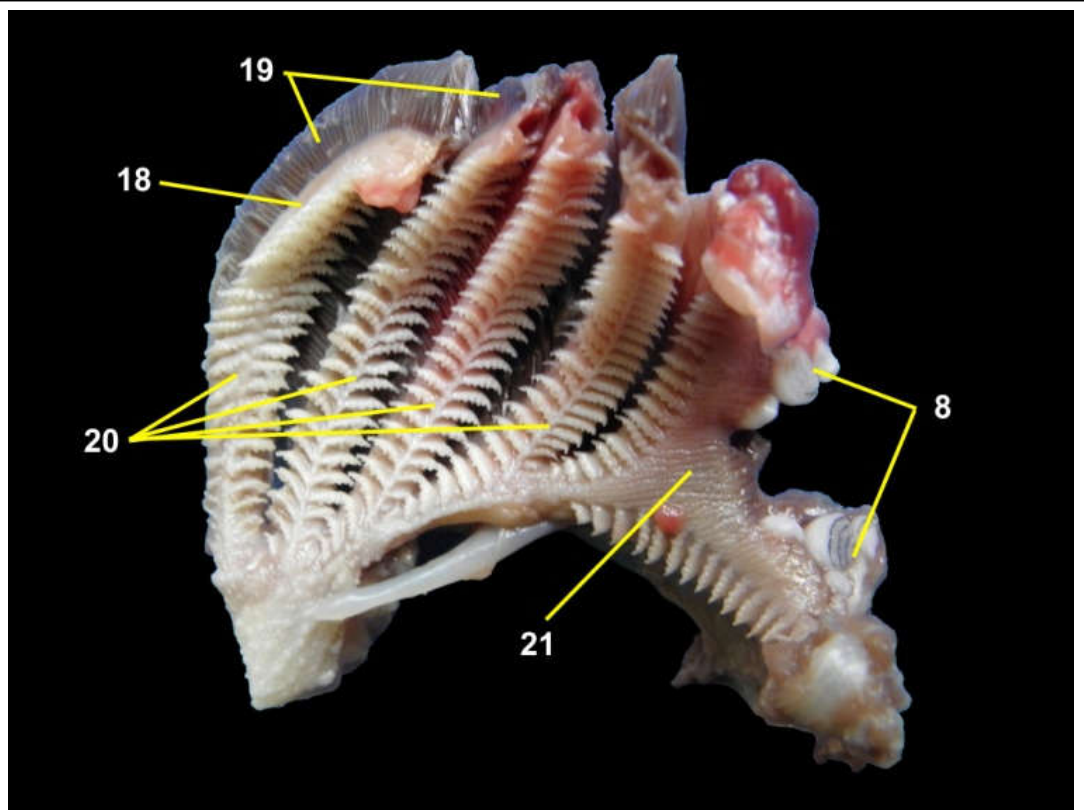

Fig (7): A photograph showing the gill structure of the common carp

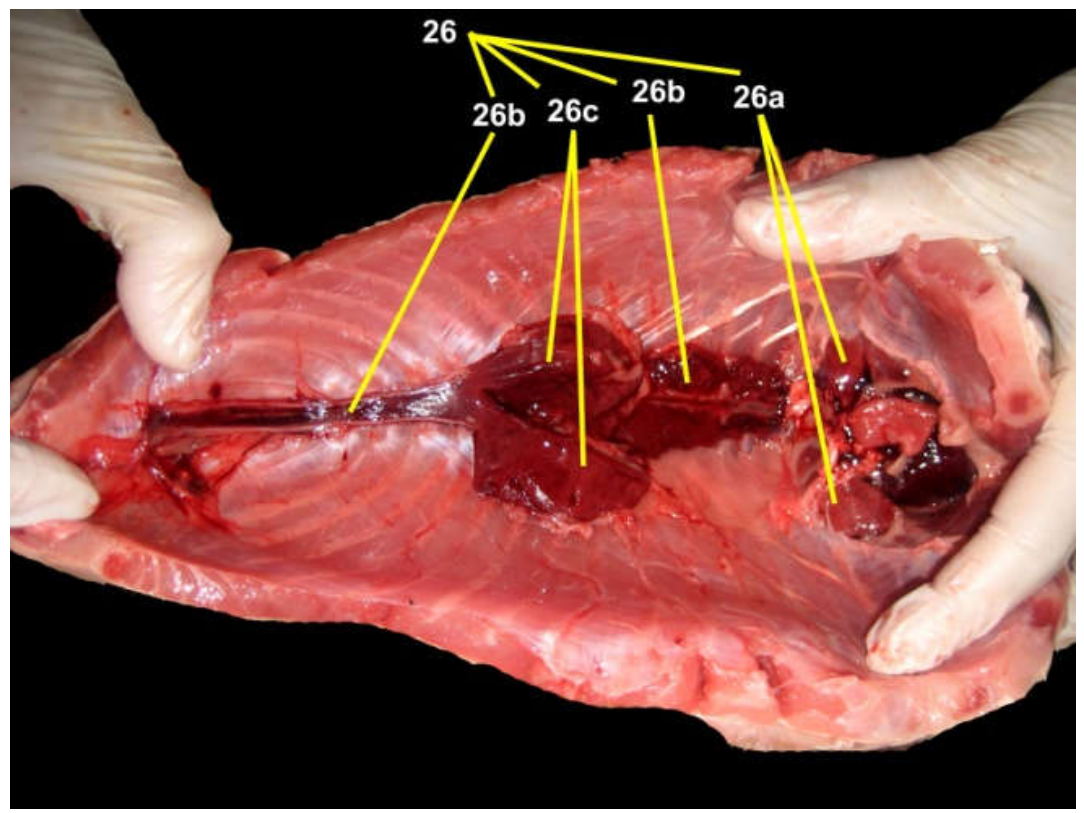

Fig (8): A photograph showing the kidney of the common carp in situ (Ventral view)

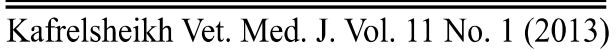


some gross morphological studies on the internal ...

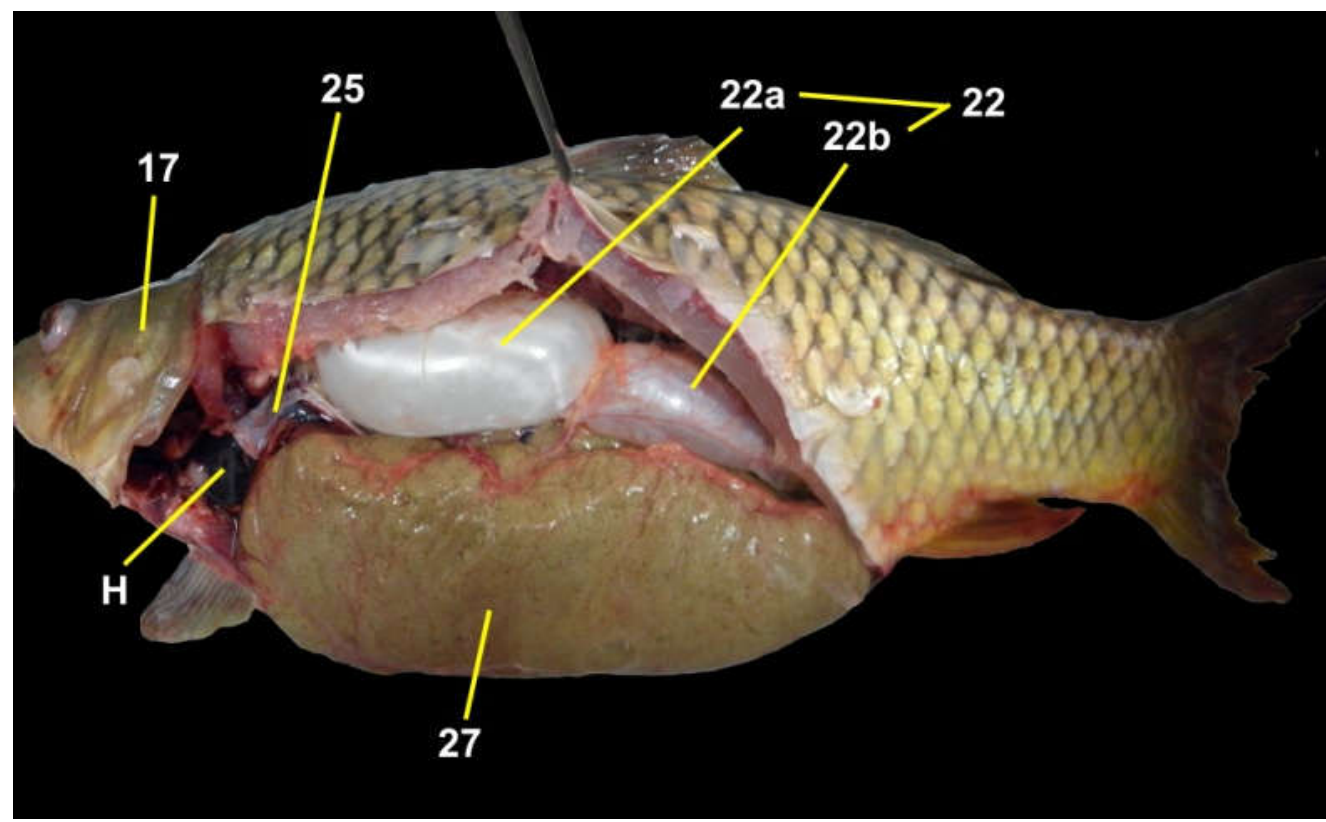

Fig (9): A photograph showing the left ovary and swim bladder of the common carp in situ

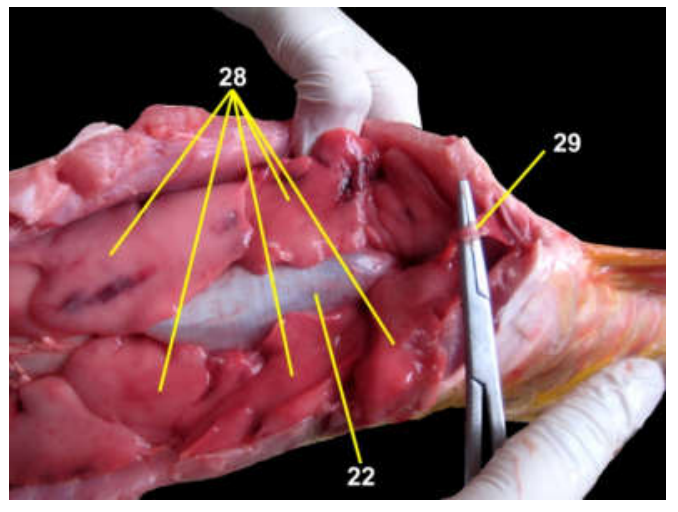

Fig (10): A photograph showing the testis and swim bladder of the common carp in situ (Ventral view)

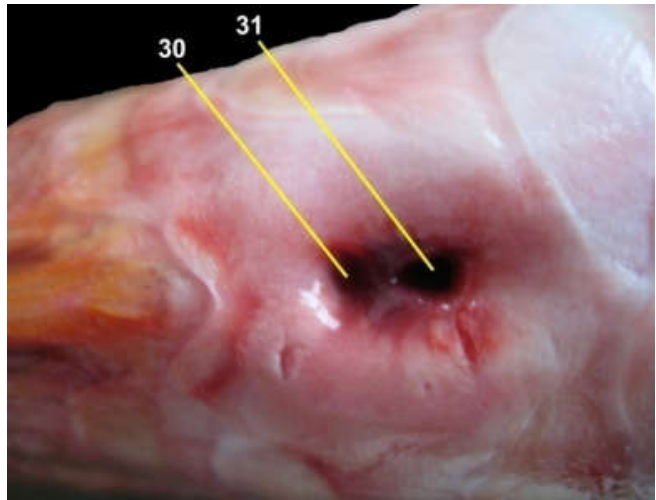

Fig (11): A photograph showing the anal and urogenital pores of the common carp in situ (Ventral view)

$\overline{\text { Kafrelsheikh Vet. Med. J. Vol. } 11 \text { No. } 1 \text { (2013) }}$ 


\section{DISCUSSION}

According to the present work the mouth opening was oriented terminally in the carp. Scott and Crossman (1973) recorded that in the trout-perch the mouth was small and slightly under snout, in the suckers fish the mouth was ventral while in the golden shiner fish the mouth notably directed upward, with chin projecting forward. The author added that the orientation and size of the mouth often indicate the specie's feeding habits. Surface feeding fish usually have an undershot, upturned (superior) mouth for feeding on insects. Fish that feed in mid water have a terminal mouth, which is usually considered the "normal" fish mouth. Predatory fish usually have a wide mouth, while omnivorous fish have smaller mouths. Bottom feeding fish generally have an under slung or inferior mouth. Often, bottom feeding species are also equipped with barbells ("whiskers"), which are tactile and taste organs used for locating food in dark or muddy waters. The barbells in the common carp were two pairs; one pair located on the middle of the upper lip and was short and thin while the other pair was laterally situated at the mouth commissure. Cat fish presented four pair barbells in the form of long filaments and were designated according to their attachment around the mouth as nasal, maxillary and chin barbells (AL- Husaini, 1949)

The present study revealed that the common carp was free from any teeth on both jaws and this was compensated by well-developed pharyngeal teeth, located in the caudal portion of the pharynx on the pharyngeal bone and were arranged in a triserial manner (3:1:1). In Cyprinus the teeth are arranged (2:1:1) as mentioned by $\boldsymbol{A L}$ - Husaini (1949).

$\overline{\text { Kafrelsheikh Vet. Med. J. Vol. } 11 \text { No. } 1 \text { (2013) }}$ 
The present results as well as those given by $\boldsymbol{A L}$ - Husaini (1949) and Meyer et al. (1977) recorded that the Stomach could not be observed in the alimentary tract of the carp. Similarly lampreys, hagfishes, chimaeras, lungfishes, and some teleost fish have no stomach at all, with the esophagus opening directly into the intestine (Sherwood and Thomas 1977). However, the study showed that the post esophageal portion of this tract formed wide hollow tube which may be designated as a stomach

In Accordance with $\boldsymbol{A L}$ - Husaini (1949) no pyloric ceca could be observed in the common carp. Sherwood and Thomas (1977) mentioned that the pyloric ceca presented in most amniotes, and also in lungfish in the form of small out pocketings, despite the name they are not homologous with the cecum of amniotes, and their purpose was to increase the overall area of the digestive epithelium. The authors added that there was no small intestine in sharks, sturgeons, and lungfish. Instead, the gut formed a spiral intestine, connecting the stomach to the rectum. In this type of gut, the intestine itself is relatively straight, but has a long fold running along the inner surface in a spiral fashion, sometimes for dozens of turns. This valve greatly increases both the surface area and the effective length of the intestine. No valves could be observed in the common carp fish.

In agreement with $\boldsymbol{A L}$ - Husaini (1949) the intestinal tract of the carp fish formed three loops. However the intestinal swelling and the ascending limb of the proximal loop recorded in the present study was designated by the latter author as the Siphonal loop. Sherwood and Thomas (1977) stated that in bony fish, the intestine was relatively short, 
typically around one and a half times the length of the fish's body. $\boldsymbol{A L}$ Husaini (1949) mentioned that there was a general relationship between the length of the intestine and feeding habits. The intestine in carnivorous fish was shorter than that of omnivores and herbivores.

In agreement with $\boldsymbol{A L}$-Husaini (1949) the liver of the Carp was relatively large and formed of multiple hepatic fragments that surrounded and dispersed between most of the intestine and was designated by the author as hepatopancreas. In Perch the liver formed of U-shaped organ, pale pink in colour and consisted of four lobes; two large lobes, right and left lobes two smaller lobes while in Tilapia the liver was formed of two lobes large left lobe and small right one (Ibrahim, 2013).

According to Gerham (1997), Zayed and Mohamed (2004) and Ahmed et al. (2008), the gill arches in the tilapia and cat fish were four pairs . On the other hand five pairs of gill arches were observed and the last pair united forming the pharyngeal bone. It is to add that the air breathing dendretic organs recorded by the authors in the cat fish could not be observed in the present study.

In accordance with Petrick (1975) in the Barbus, and Labeo fishes and Meyer et al (1977) in the carp fishes the swim bladder of the common carp was constricted into two chambers an anterior and a posterior connected by an isthmus. Petrick (1975) in Siluriformes fishes mentioned heart-shaped swim bladder that divided by a longitudinal and a transverse septum into three chambers; an anterior a right and a left posterior chamber. In the common carp the cavities of both chambers were undivided by any internal septa and were communicated through narrow internal foramen through the connecting isthmus. The swim bladder of the common carp could be considered as an open, Kafrelsheikh Vet. Med. J. Vol. 11 No. 1 (2013) 
physostomous type, as it was connected to the cranial portion of the esophagus through a pneumatic duct. Petrick (1975) also recorded physostomous swim bladder in the Barbus, Siluriformes and Labeo fishes while that of the Cichlid was physoclistic without connection to the gut. The swim bladder was often absent in cartilaginous fishes, as shark and fast swimming fishes, as the tuna and mackerel families (Kardong, 2008). It is to add that, the swim bladder of the carp fish did not connected to the inner ear. On the contrary Parmentier et al. (2011) mentioned that the swim bladder formed two bilateral horns connected to the inner ear and played a role in enhancing hearing.

Petrick (1975) also recorded the presence of gas gland and Rete mirabile on the wall of the swim bladder in Cichlidae and added that these glands formed patches on the ventral wall of the bladder which were of a definite shape and size for different species. Neither Rete nor glands were observed in the common Carp, similar to that recorded by the latter author in Barbus, Siluriformes and Labeo fishes. He also added that Hydrocynus fish presented gas glands although Rete mirabile was not observed. The gas content of the bladder is controlled through a Rete mirabile through gas exchange between the bladder and the blood (Kardong, 2008).

In the common carp the head kidneys were in the form of two oval bodies and separated from each other in the midline and also from the trunk kidneys by wide gap. It may be added that the trunk kidneys were further differentiated into an anterior thick and a posterior thin portion. In between these portions, an expanded three sided ventral lobes were formed. Similar findings were also recorded by Kumar and Tembhre (1996) in the Carp but they described the later lobes as two tubes like structures. 


\section{REFERENCES}

- Ahmed, A. E.; Mohamed, K.; Ahmed, S.A. and Masoud, F. (2008): Anatomical, light and scanning Electron Microscopic studies on the Air Breathing Dentretic organ of Sharp Tooth cat fish (Clarias gariepinus). Journal of Veterinary Anatomy; 1(1):29-37.

- AL-husaini, A. H. (1949): On the Functional Morphology of the Alimentary Tract of Some Fish in Relation to Differences in their Feeding Habits: Anatomy and Histology. Quarterly Journal Microscopical Science, 90 (2):110-131.

- Bakos J. and Gorda, S. (2001): Genetic resources of common carp at the Fish Culture Research Institute, Szarvas, Hungary, FAO Fisheries Technical Paper No. 417 , Rome, FAO.2001.106p.

- Gerham, J. B. (1997): Air Breathing Fishes. Pupplished by Academic Press, a division of Harcourt Brace and company 525 B,suite1900,San Diego, Caliornia.

- Ibrahim, A.M. (2013): Construction of Anatomical Learning Modules of Some Fresh Water Fish Obtained from the Egyptian Zone of the River Nile. Thesis M.V.Sc. Faculty of Veterinary Medicine Cairo University.

- Kardong, K. (2008): Vertebrates: Comparative anatomy, function, evolution (5th ed.). Boston: McGraw-Hill. ISBN 0-07-304058-4.

- Kottelat, M. and J. Freyhof, (2007): Handbook of European freshwater fishes. Publications Kottelat, Cornel, Switzerland 646 p. 
- Kumar, S. and Tembhre, M. (1996): Anatomy and physiology of fishes. Published in Vikas puplishing house pvtlitd 576 Masjjd Road, Jangpura, New Delhi 110014 First floor, N.S Bhawan, Bhawan, $4^{\text {th }}$ Cross, $4^{\text {th }}$ Main,Gandhi Nagar,Bangalore-560 009.

- Meyer, V.; Krefft, G. and Lillelund, K. (1977): Atlas zur Anatomie und Morphologie der Nutzfische Verlag Paul Parey -Hamburg Und Berlin. 62 (4): 557.

- Parmentier, E., Mann, K. and Mann, D. (2011): Hearing and morphological specializations of the mojarra (Eucinostomus argentous. The Journal of Experimental Biology 214, 2697-2701

- Petrick, F.O. (1975): Anatomy of the swimbladder of seven families of Transvaal fresh water fishes. Journal of the Limnological Society of Southern Africa Vol. (1), Issue 1.

- Scott, W.B., and Crossman, E.J. (1973): Freshwater fishes of Canada. Fisheries Research Board of Canada Bulletin 184

- Sherwood, R.A. and Thomas, P. S. (1977): The Vertebrate Body. Philadelphia, PA: Holt-Saunders International. pp. 161-170.

- Zayed, A.E. and Mohamed, S.A. (2004): Morphological study on the gills of two species of fresh water fishes: Oreochromis Niloticus and Clarias gariepinus. Annals of Anatomy,186(4):295-304. 


\section{بعض اللراسات المورفولوجيه على التشريح الداخلي لسمك المبروك العادي في مصر}

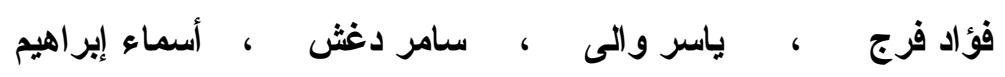

أجرى البحث على عشر سـكات مبروك عـادى تتر اوح أوز انها بين 0, 1- 0, ب ك.ج تم

تشريحها بدقـه لدر ســة الأجهزة: الهضمي، التتفسي و البولي التتاسلي. وقـد تـم دراسـة الصفات التشريحية للفم و البلعوم و الأمعاء و الكبد و المر ارة والطحسال و الخياثـيم والمثانـة السباحة و الكلى و المبيض و الخصية.

وقد نم وصف هذه الأحشاء وتم تصوير العينات بعد تشريحها ، وذلك لتوضيح النتائج. كمـا نوقثت النتائج المتاحة في الدراسة مع ما تم الحصول عليه في الأعمال السابقة في الأسماك. 